ERR A T UM

G. Pizzo $\cdot$ G. A. Scardina $\cdot$ P. Messina

\title{
Effects of a nonsurgical exercise program on the decreased mouth opening in patients with systemic scleroderma
}

Published online: 22 November 2003

(C) Springer-Verlag 2003

\section{Clin Oral Invest (2003) 7:175-178}

The dates of receipt and acceptance were omitted. They were:

Received: 2 December 2002

Accepted: 21 May 2003

The online version of the original article can be found at http://dx.doi.org/10.1007/s00784-003-0216-5

G. Pizzo (๘)

Department of Oral Sciences, Section of Periodontology,

University of Palermo,

Via del Vespro 129, 90127 Palermo, Italy

e-mail: giuseppe.pizzo@inwind.it

Fax: +39-091-6552203

G. A. Scardina - P. Messina

Department of Oral Sciences, Section of Oral Medicine,

University of Palermo,

90127 Palermo, Italy 